Disorders of the Nervous System

\title{
Atypical Localization and Dissociation between Glucose Uptake and Amyloid Deposition in Cognitively Normal APOE*E4 Homozygotic Elders Compared with Patients with Late-Onset Alzheimer's Disease
}

(D) José V. Pardo, ${ }^{1,2}$ Joel T. Lee, ${ }^{1,2}$ and for the Alzheimer's Disease Neuroimaging Initiative*

DOI:http://dx.doi.org/10.1523/ENEURO.0396-17.2018

${ }^{1}$ Cognitive Neuroimaging Unit, Mental Health Service Line, Minneapolis Veterans Health Care System, Minneapolis, MN 55417 and ${ }^{2}$ Department of Psychiatry, University of Minnesota, Minneapolis, MN 55455

\section{Visual Abstract}

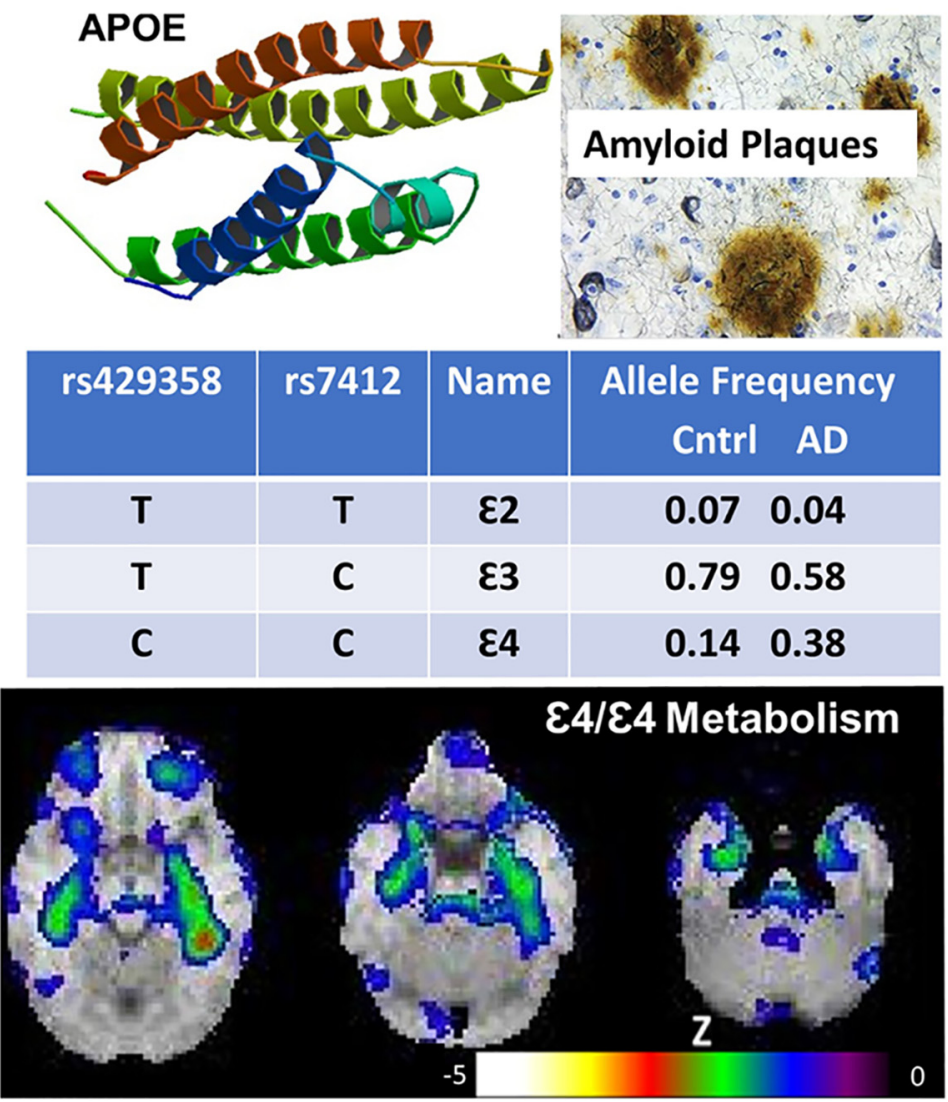

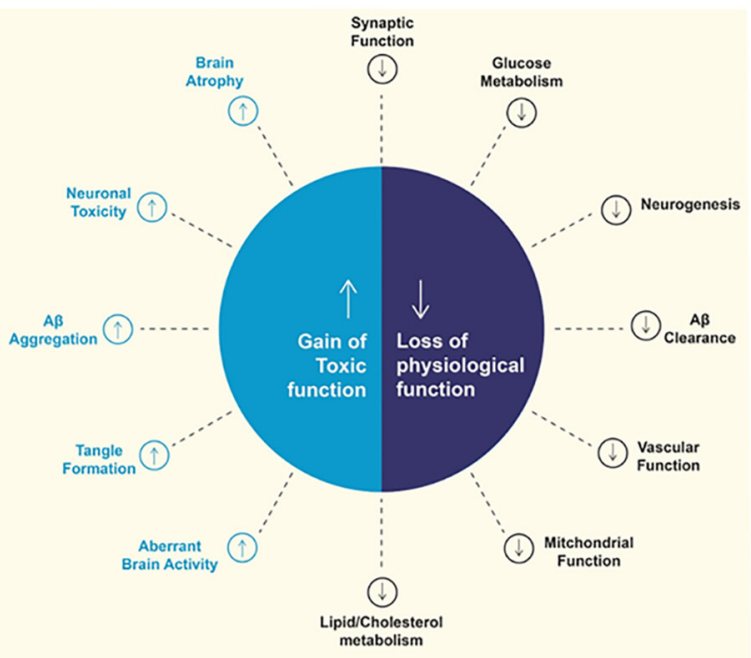

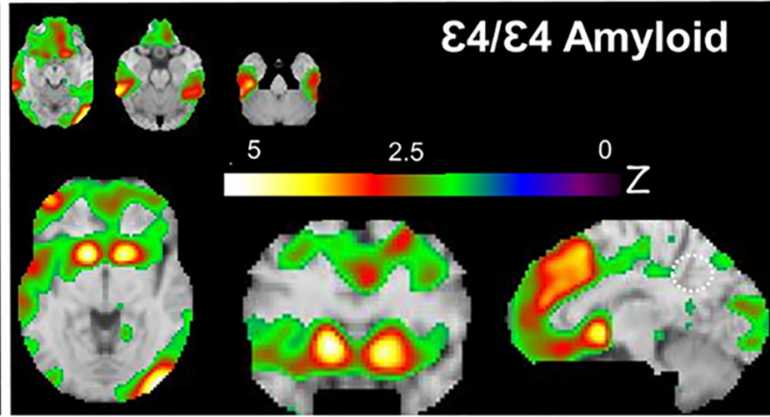




\section{Significance Statement}

$A P O E * E 4$ has the largest single effect size of any common variant for any human disease. APOE*E4 homozygotes increase the risk of late-onset Alzheimer's disease (LOAD) 15-fold. Research indicates that interventions for $A D$ must occur decades before onset of symptoms. However, the phenotypic antecedents and pathophysiology of LOAD remain limited in characterization. APOE*E4 homozygotes offer a unique opportunity to characterize preclinical $A D$. Here, neuroimaging of cognitively normal, elderly $A P O E * E 4$ homozygotes reveals decreased medial temporal metabolism and increased lenticular amyloid deposition in those at high risk for developing LOAD. In comparison to LOAD, an atypical pattern of change in metabolism and amyloid distribution as well as a dissociation between these two measures arose in homozygotes compared to noncarriers.

Alzheimer's disease (AD) progresses insidiously over decades. Therefore, study of preclinical AD is critical to identify early pathophysiological changes as potential targets for prevention or treatment. The brain processes at the preclinical stage remain minimally understood. Aside from age, the E4 allele of APOE flags a group at particularly high risk of late-onset AD (LOAD). Studies of these individuals could provide insights about the ontogenesis of $A D$ offering clues for novel treatment strategies. To this end, cognitively normal, $A P O E * E 4$ homozygotes from the Alzheimer's Diseases Neuroimaging Research Initiative database (ADNI-LONI) provided fluorodeoxyglucose and amyloid (florbetapir) PET scans ( $n=8$ and 7 , respectively; mean age 76 years). Their scans were compared to those of matched cognitively normal elders who were not E4 carriers. There was dissociation in the distribution between glucose uptake and amyloid deposition in the homozygotes. Peak hypometabolism localized bilaterally along the medial temporal cortex. In contrast, peak amyloid deposition localized principally to the putamen, a finding also seen in preclinical carriers of autosomal dominant $A D$ mutations and preclinical $A D$ associated with Down syndrome. Additional regions of amyloid deposition in homozygotes were medial prefrontal cortices including the anterior cingulate, middle and inferior frontal cortices, and middle and inferior occipital cortices. These findings contrast with those reported for LOAD. These data begin to characterize elders with normal cognition despite high $A D$ risk in comparison to the known phenotypes of patients with LOAD.

Key words: Aging; Alzheimer's Disease Neuroimaging Initiative; amyloid; APOE*E4; brain metabolism; positron emission tomography

\section{Introduction}

The disease process of Alzheimer's disease (AD) begins insidiously decades before enough brain damage occurs to require accessing medical care. Increasingly, there is consensus that prevention is critical and that interventions will be best when used early. The two most significant risk
Received October 23, 2017; accepted February 6, 2018; First published February 15, 2018.

The authors declare no competing financial interests.

Author contributions: JVP and JTL designed the research, analyzed data, contributed analytic tools, and wrote the paper. ADNI provided data as indicated in Acknowledgments.

"Data collection and sharing for this project was funded by the Alzheimer's Disease Neuroimaging Initiative (ADNI; National Institutes of Health Grant U01 AG024904) and DOD ADNI (Department of Defense award number W81XWH12-2-0012). ADNI is funded by the National Institute on Aging, the National Institute of Biomedical Imaging and Bioengineering, and through generous contributions from the following: AbbVie, Alzheimer's Association; Alzheimer's Drug Discovery Foundation; Araclon Biotech; BioClinica, Inc.; Biogen; BristolMyers Squibb Company; CereSpir, Inc.; Cogstate; Eisai Inc.; Elan Pharmaceuticals, Inc.; Eli Lilly and Company; Eurolmmun; F. Hoffmann-La Roche Ltd and its affiliated company Genentech, Inc.; Fujirebio; GE Healthcare; IXICO Ltd.; Janssen Alzheimer Immunotherapy Research \& Development, LLC.; Johnson \& Johnson Pharmaceutical Research \& Development LLC.; Lumosity; Lundbeck; Merck \& Co., Inc.; Meso Scale Diagnostics, LLC.; NeuroRx Research; Neurotrack Technologies; Novartis Pharmaceuticals Corporation; Pfizer Inc.; Piramal Imaging; Servier; Takeda Pharmaceutical Company; and Transition Therapeutics. The Canadian Institutes of Health Research is providing funds to support ADNI clinical sites in Canada. Private sector contributions are facilitated by the Foundation for the National Institutes of Health (www.fnih.org).
The grantee organization is the Northern California Institute for Research and Education, and the study is coordinated by the Alzheimer's Therapeutic Research Institute at the University of Southern California. ADNI data are disseminated by the Laboratory for Neuro Imaging at the University of Southern California.This work was funded by VA 5I01CX000501 (JVP). This material is the result of work supported with resources and the use of facilities at the Minneapolis Veterans Health Care System, Minneapolis, MN. The contents do not represent the views of the U.S. Department of Veterans Affairs or the United States Government.

Data used in preparation of this article were obtained from the Alzheimer's Disease Neuroimaging Initiative (ADNI) database (adni.loni.usc.edu). As such, the investigators within the ADNI contributed to the design and implementation of $\mathrm{ADNI}$ and/or provided data but did not participate in analysis or writing of this report. A complete listing of ADNI investigators can be found at http://adni.loni.usc.edu/wpcontent/uploads/how_to_apply/ADNI_Acknowledgement_List.pdf.

Correspondence should be addressed to José V. Pardo, MD, PhD, Minneapolis VA Medical Center, One Veterans Drive, Minneapolis, MN 55417. E-mail: jose.pardo@va.gov.

DOI:http://dx.doi.org/10.1523/ENEURO.0396-17.2018

Copyright (C) 2018 Pardo et al.

This is an open-access article distributed under the terms of the Creative Commons Attribution 4.0 International license, which permits unrestricted use, distribution and reproduction in any medium provided that the original work is properly attributed. 
factors for $A D$ are age and the $A P O E * E 4$ gene (also referred to as E4).

Having two $A P O E * E 4$ alleles gives an odds ratio for $A D$ of almost 15 (Farrer et al., 1997). APOE*E4 is the common variant with the greatest known effect size for association to any human disease. This level of risk is like that for known Mendelian disease-causing mutations such as the breast cancer gene, BRACA (Genin et al., 2011). E4 homozygotes have earlier onset of cognitive decline by 25-7 years (Blacker et al., 1997; Sando et al., 2008). Therefore, studies of carriers of $A P O E * E 4$ have the potential to reveal insights into the early pathophysiology of AD. Recent advances in technology offer unique opportunities to study these individuals noninvasively.

Early in the development of $A D$, amorphous amyloid deposits occur throughout the brain initially in the inferior aspects of the frontal, temporal, and occipital lobes, later spreading diffusely throughout the neocortex (Braak and Braak, 1991). Amyloid deposition in the form of neuritic plaques containing the amyloid- $\beta(A \beta)$ protein develop with variable consistency, density, and distribution. Tangles and neuropil threads generally develop before plaques. The presence of $A P O E * E 4$ is associated with amyloid deposition even in cognitively normal elders (Morris et al., 2010). The amount and distribution of neuritic plaques vary widely between individuals at similar disease stages (Braak and Braak, 1991). As many as one-third of E4 noncarriers diagnosed clinically with AD are characterized as amyloid negative on neuropathologic assessment (Monsell et al., 2015). In that study, approximately onehalf of those with a primary diagnosis of mild to moderate $A D$ and low cerebral $A \beta$ had extensive neurofibrillary degeneration.

The amount of fibrillar amyloid throughout the brain identifies both past and future decline in cognition (Doraiswamy et al., 2014; Donohue et al., 2017). PET studies of $A D$ indicate that fibrillar amyloid and hypometabolism arise early in the posterior cingulate cortex/precuneus (Minoshima et al., 1994, 1997; Scheff et al., 2015). Although there is often overlap between cortical thinning, amyloid deposition, and hypometabolism, dissociations are not unusual (Murray et al., 2014).

Abnormal tau begins to deposit in the transentorrhinal cortex even in nondemented individuals (Braak and Braak, 1991; Bouras et al., 1994; Braak and Del Tredici, 2015). Subsequently, tau spreads to limbic allocortices including the hippocampal, cingulate, retrosplenial, and orbitofrontal cortices. With advanced AD, tau spreads into the neocortex. Tau staging correlates best with level of cognitive function and appears consistent across individuals with similar symptoms and degrees of clinical dysfunction (Braak and Braak, 1991; Ossenkoppele et al., 2016). $A P O E * E 4$ status and tau pathology are not correlated (Morris et al., 2010). Although there is frequent overlap between amyloid, atrophy, and tau, dissociation between markers can occur; tau and atrophy tend to co-occur more frequently (Xia et al., 2017).

Biomarker development has advanced greatly the characterization of preclinical and early AD. As many as $30 \%$ of cognitively normal individuals $>65$ years of age have significant amyloid deposition (Murray et al., 2014). PET imaging has demonstrated amyloid deposition in both cognitively intact and impaired carriers of mutations in PSEN1, PSEN2, and APP, who typically have early onset of AD (Klunk et al., 2007; Remes et al., 2008; Fleisher et al., 2012; Shi et al., 2015; Rodriguez-Vieitez et al., 2016). Similarly, amyloid deposition has been found in those with and without evidence of cognitive decline who have Down syndrome (trisomy 21) with development of AD during middle age (Handen et al., 2012; Lao et al., 2016; Rafii et al., 2017).

Cognitively normal healthy elders homozygous for $A P O E * E 4$ and therefore at very high risk of developing $A D$ could provide data relevant to preclinical AD. Such information can guide future research and hint at pathophysiological mechanisms, particularly given recent evidence from transgenic mice that $A P O E * E 4$ may provide a gainof-toxic-function independently of amyloid (Shi et al., 2017). To this end, PET scans of glucose uptake with $\left[{ }^{18} \mathrm{~F}\right]$ fluorodeoxyglucose (FDG), a proxy for regional cerebral metabolism, and of amyloid deposition from $\left[{ }^{18} \mathrm{~F}\right]$ florbetapir scans were downloaded from the Alzheimer's Disease Neuroimaging Initiative (ADNI) database. Scans from E4 homozygotes were compared to scans from $A P O E * E 4$ noncarriers.

\section{Subjects and Methods}

\section{Participants}

Data used in the preparation of this article were obtained from the Alzheimer's Disease Neuroimaging Initiative (ADNI) database (adni.loni.usc.edu; RRID:SCR_003007; accessed May 2017). The ADNI was launched in 2003 as a public-private partnership, led by Principal Investigator Michael W. Weiner, MD. The primary goal of ADNI has been to test whether serial magnetic resonance imaging (MRI), positron emission tomography (PET), other biological markers, and clinical and neuropsychological assessment can be combined to measure the progression of mild cognitive impairment $(\mathrm{MCl})$ and early $\mathrm{AD}$.

All E4/E4 subjects $(n=8)$ included here had no memory complaints or functional impairments and were identified as normal cognitively based on neurologic and neuropsychological testing; Mini-Mental Status Exam (MMSE) score 24-30; absence of clinically significant findings on screening MRI; Clinical Dementia Rating (CDR) 0; Geriatric Depression Scale (GDS) $\leq 6$; and Hachinski score $<4$. This designation was based on the diagnosis closest to the time of the first imaging scan. Imaging results (e.g., cortical thinning, FDG, amyloid) were not used to define normality, so normal volunteers could have abnormalities in imaging scans subsequently. One homozygote did not get an amyloid scan. The comparison group was likewise characterized as normal but lacked E4 carriers. Demographic characteristics and related data of the homozygotes are shown in Table 1.

Additionally, late-onset AD (LOAD) subjects $(n=8)$ from $A D N I$ with very mild $A D$ (CDR sum of boxes mean $=3.4$; range 2-4.5; $S D=1$ ) and similar ages to the E4/E4 group were selected as a patient group for comparison to the 
Table 1. Subject demographics and related data

\begin{tabular}{|c|c|c|c|c|c|c|c|c|c|}
\hline FDG ID \# & AV45 ID \# & Age (y) & Sex & MMSE & Hach & GDS & SUVR & Months & $D x$ \\
\hline 009_S_4388 & 009_S_4388 & 67 & $\mathrm{M}$ & 29 & 1 & 2 & 0.97 & 0.9 & $\mathrm{MCl}$ \\
\hline 013_S_4580 & 013_S_4580 & 70 & $\mathrm{~F}$ & 30 & 1 & 2 & 1.03 & 24 & $\mathrm{NI}$ \\
\hline 014_S_0520 & NA & 82 & $F$ & 30 & 0 & 1 & & 8.8 & $\mathrm{MCl}$ \\
\hline 014_S_4577 & 014_S_4577 & 85 & M & 29 & 1 & 0 & $1.17 *$ & $0.8^{\dagger}$ & $\mathrm{MCl}$ \\
\hline 027_S_5083 & 027_S_5083 & 74 & M & 28 & 0 & 1 & 1.05 & 24 & $\mathrm{NI}$ \\
\hline 032_S_4348 & 032_S_4348 & 66 & $\mathrm{~F}$ & 30 & 0 & 5 & $1.42 *$ & 7.2 & $\mathrm{NI}$ \\
\hline 033_S_4179 & 033_S_4179 & 83 & $M$ & 30 & 1 & 1 & $1.53 *$ & 52 & $\mathrm{NI}$ \\
\hline 082_S_4339 & 082_S_4339 & 84 & M & 29 & 1 & 0 & $1.41 *$ & 25 & $\mathrm{NI}$ \\
\hline
\end{tabular}

Reference group matched for age (mean 75 years, range 60-94, SD 6) and education (mean 17 years, range 8-20). Months denote time interval between closest assessment and FDG PET (months to last diagnosis of normal after imaging; ${ }^{\dagger}$ months to last diagnosis of normal before imaging). *, amyloid positive (per ADNI). AV45, florbetapir; MMSE, Mini-Mental Status Exam score; Hach, Hachinski score; GDS, Geriatric Depression Scale; SUVR, standardized uptake value ratio (per $\mathrm{ADNI}$ ); $\mathrm{NA}$, scan not available/done; $\mathrm{NI}$, normal; $\mathrm{MCl}$, mild cognitive impairment; Dx, last recorded diagnosis.

observations on asymptomatic homozygotes. As reviewed in the Discussion, there is already an extensive convergent literature on metabolic changes in $A D$.

\section{Methods}

All methods are described in detail at the ADNI database (adni.loni.usc.edu) following procedures approved by the institutional review boards. All scanning manufacturer's corrections were "On" (decay, randoms, scatter, etc.).

Briefly, subjects were injected intravenously with 185 $\mathrm{MBq}(5 \mathrm{mCi})\left[{ }^{18} \mathrm{~F}\right] \mathrm{FDG}$ for the glucose-uptake scan. The volunteer rested with eyes and ears open in a quiet, dim room for $20 \mathrm{~min}$. Thirty minutes after injection, emission scans were obtained for $30 \mathrm{~min}$. Scans were corrected for measured attenuation using low-dose CT scans.

Amyloid scans were acquired within 2 wk before or after the FDG scans. The subjects were injected intravenously with $370 \mathrm{MBq}(10 \mathrm{mCi})\left[{ }^{18} \mathrm{~F}\right]$ florbetapir. After a 50 -min uptake period, an emission scan was obtained for $20 \mathrm{~min}$. Scans were corrected for measured attenuation using low-dose CT scans.

\section{Image analysis}

All scans consisted of a $160 \times 160 \times 96$ image grid with a voxel size of $1.5-\mathrm{mm}$ cubic voxels. Scanner-specific filters were used to obtain an image resolution of $\sim 8 \mathrm{~mm}$ full width at half-maximum (FWHM) regardless of scanner model. Images were inspected visually for potential artifacts. The FDG PET scans were normalized to a wholebrain uptake of 1000 counts. The amyloid scans were normalized based on the cerebellar cortex. All scans were anatomically coregistered to a template using Neurostat (Stereotactic Image Registration; v.7.1; S. Minoshima, University of Utah). Minima and maxima of the $z$-images were localized and quantitated with in-house software using an averaged, roving, 3-voxel cube. As routine for FDG PET studies at this resolution, a $z$-score $\geq 3.0$ was defined as significant. The localization of structures was aided through use of the Talairach daemon (Lancaster et al., 2000).

\section{Results}

The demographics and related data of the APOE*E4 homozygotes are presented in Table 1. The average age was $76 \mathrm{y}$, range $66-85$, SD 8 . Three volunteers were women. The average of MMSE scores was 29. SUVR ranged from 0.93 to 1.53 (mean 1.02; SD 0.04); four were classified as amyloid positive by ADNI criteria. Hachinski scores ranged from 0 to 1 with average of 0.5 . The average GDS rating was 1.5. The reference control group (i.e., non-E4 carriers; including E2 and E3 genotypes) was matched for age (75 y old, range 60-94, SD 6) and educational level (17 y). The reference group for FDG PET included 282 subjects; 144 males, 138 females; education range 8-20 years, mean $=16.6$; 254 European Americans, 17 African Americans; 6 Asian Pacific Americans; and 1 Native American. The reference control group for amyloid imaging included 263 subjects; 133 males, 130 females; 235 European Americans, 17 African Americans, 6 Asian Pacific Americans; and 1 Native American.

Fig. 1 (top) shows the peak regions of hypometabolism based on $\left[{ }^{18} \mathrm{~F}\right] \mathrm{FDG}$ when comparing subjects who were $A P O E * E 4$ homozygotes versus $A P O E * E 4$ noncarriers. Both medial temporal cortices were symmetrically hypometabolic (left greater than right). The peak of hypometabolism mapped to left parahippocampal gyrus, Brodmann 37, at $(-39,-37,-11)$ with $z=-3.0$. Although below the significance threshold, the second most hypometabolic peak localized to the left hippocampus at $(-33$, $-15,-14)$ with $z=-2.6$. No other regions were hypometabolic including the putamen or ACC. No regions showed increased metabolism in the contrast between homozygotes and noncarriers.

Fig. 1 (bottom) shows the results for the same metabolism contrast (LOAD vs. noncarrier). There is medial temporal hypometabolism similar in magnitude to that seen in E4/E4. As expected, large foci of hypometabolism localized to the PCC, ACC, and lateral parietal and inferior temporal cortices.

Fig. 2 (top) shows the loci of peak deposition of amyloid based on $\left[{ }^{18} \mathrm{~F}\right]$ florbetapir in $A P O E * E 4$ homozygotes when compared to the E4 noncarrier group. The peaks with highest magnitude localized to the lenticular nuclei, particularly the bilateral putamen. A broad region of amyloid deposition occurred in the ACC as well as medial and middle prefrontal gyri, inferior temporal, and occipital gyri. Other foci are listed in Table 2. No amyloid mapped to the PCC. 


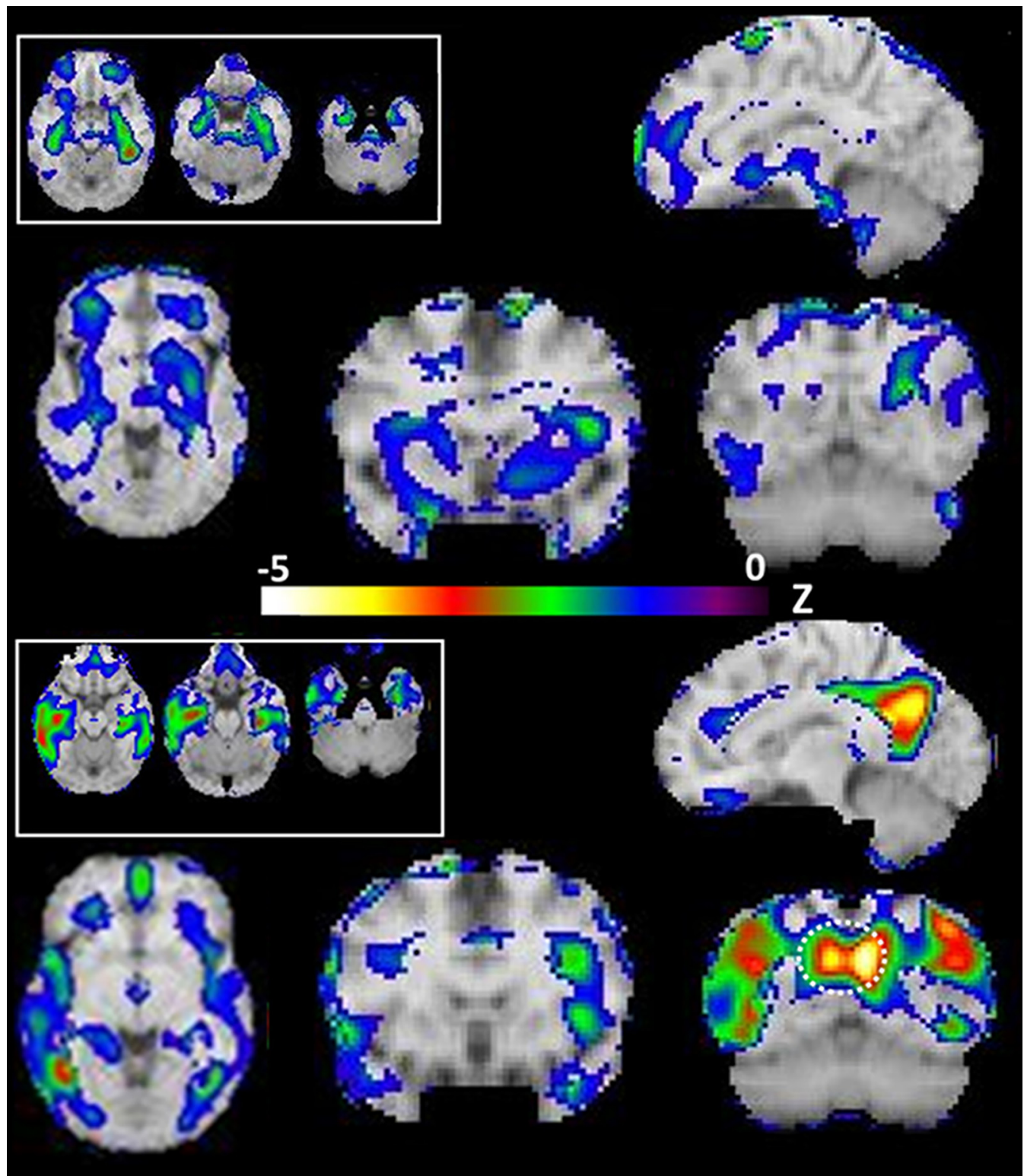

Figure 1. Top (above color bar): FDG uptake in E4 homozygotes contrasted with E4 noncarrier reference group. Transverse sections (top left inset) are taken from left to right at $z=-11,-18$, and $-25 \mathrm{~mm}$ below the intercommissural plane, respectively. The peak (red; $z=-3.0)$ is in the left parahippocampus. Note sequential inferiorly directed medial temporal lobe structures. Larger sections from lower left to upper right: $z=-2, y=12, y=-60, x=-10$, respectively. Note minimal hypometabolism throughout including striatum. For illustrative purposes, the threshold was set to $z=-3$. Note minimal or no hypoactivity in PCC and parietal cortex in E4 homozygotes. Bottom: FDG uptake in very mild AD contrasted with E4 noncarrier reference group. Transverse sections (top left inset) are taken from left to right at $z=-11,-18$, and $-25 \mathrm{~mm}$ below the intercommissural plane, respectively. Note sequential inferiorly directed medial temporal lobe structures. Larger sections from lower left to upper right: $z=-2, y=12, y=-60, x=-10$, respectively. For illustrative purposes, the threshold was set to $z=-3$. Note marked hypometabolism in bilateral lateral parietal cortex and $\mathrm{PCC} /$ precuneus (dashed circle). Left side of brain is on right side of image (radiologic convention).

Fig. 2 (bottom) shows the results for the same amyloid contrast (LOAD vs. noncarrier). Most of the cortex shows extensive deposition of amyloid. The bilateral putamen show the greatest magnitude of deposition along with very heavy deposits in PCC/precuneus, ACC, as well as prefrontal, lateral parietal, and lateral temporal cortices. As reviewed below, these results converge with extensive literature but are presented for direct comparison with the homozygotes.

\section{Discussion}

\section{Novel findings in E4 homozygotes}

This report provides several new findings. The literature relevant to these results based on metabolic and amyloid imaging as well as limitations is presented in the following sections.

(1) Medial temporal lobe (MTL) metabolism was reduced in E4 homozygotes, like the results found 


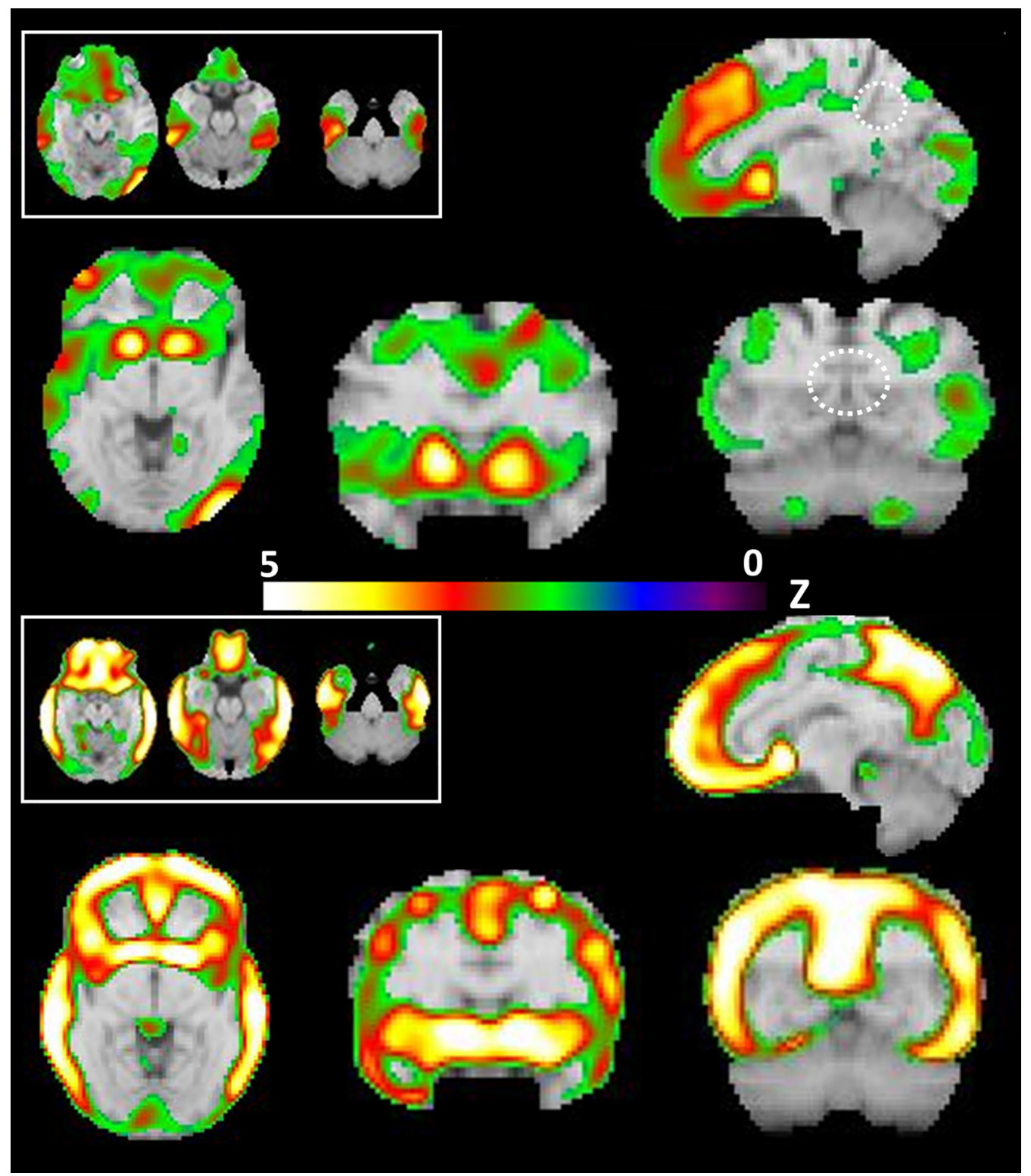

Figure 2. Top (above color bar): Amyloid deposition in cognitively normal, E4 homozygotes contrasted with E4 noncarriers. Transverse sections through MTL (top left inset) are from left to right at $z=-11,-18,-25$, respectively. Larger sections from lower left to upper right: $z=-2, y=12, y=-60, x=-10$, respectively. Note heavy amyloid deposition in the striatum, specifically the putamen. The PCC/precuneus (dashed circle) appear to have minimal amyloid, unlike the typical pattern in LOAD (see bottom panel). For illustrative purposes, the threshold was set to $z=-3$. Bottom panel: Amyloid deposition in very mild $A D$ contrasted with $E 4$ noncarriers. Transverse sections through MTL (top left inset) are from left to right at $z=-11,-18,-25$, respectively. Larger sections from lower left to upper right: $z=-2, y=12, y=-60, x=-10$, respectively. Note extensive amyloid deposits throughout the cortex, especially PCC/precuneus, and the striatum. Left side of brain is on right side of image (radiologic convention); color bar indicates $z$-scores.

here in LOAD, albeit the latter had more extensive lateral temporal changes. Nevertheless, reports of MTL metabolism in relation to E4 status have been mixed. Although cognitively intact E4 homozygotes are widely considered to show patterns of hypometabolism similar to those of patients with early LOAD, there are also numerous regions where they differ; e.g., E4 homozygotes show more extensive hypometabolism in the prefrontal cortex than those with early $A D$.
(2) E4 homozygotes did not show the anticipated parietal hypometabolism found by others, as reviewed below. Examining all hypometabolic foci, a PCC region occurs at $z=-2.0$, far below the significance cutoff, which could be a type II error given the small sample size. However, similar sample sizes in $\mathrm{MCl}$ or AD show robust PCC hypometabolism as seen in LOAD here. The E4 homozygotes in this study were older than in other studies. The absence of parietal hypometabolism could reflect a degree of resilience 
Table 2. Amyloid deposits in cognitively normal E4 homozygotes contrasted with E4 noncarriers
Structure

Putamen

Inferior occipital Brodmann area 18

Putamen

Middle occipital Brodmann area 19

Inferior temporal Brodmann area 20

ACC Brodmann area 32

ACC Brodmann area 32

Middle frontal Brodmann area 8

Brodmann area 9

Inferior temporal Brodmann area 20

Middle frontal Brodmann area 10

Medial frontal Brodmann area 9

Middle frontal Brodmann area 8

Brodmann area 9

Brodmann area 36

Brodmann area 6

Inferior temporal BA 20

Inferior temporal BA 20

Brodmann area 10

Superior temporal Brodmann area 22

Inferior temporal Brodmann area 20

Premotor Brodmann area 6

Middle temporal Brodmann area 21
Peak location $^{a}$

$\begin{array}{llll}15 & 12 & 0 & 4.7\end{array}$

$\begin{array}{llll}-35 & -85 & -5 & 4.6\end{array}$

$\begin{array}{llll}-15 & 12 & -2 & 4.5\end{array}$

$\begin{array}{llll}-44 & -73 & -9 & 4.2\end{array}$

$\begin{array}{llll}55 & -37 & -18 & 4.1\end{array}$

$\begin{array}{llll}-6 & 21 & 36 & 4.0\end{array}$

$\begin{array}{llll}-8 & 23 & 45 & 4.0\end{array}$

$\begin{array}{llll}28 & 26 & 47 & 4.0\end{array}$

$\begin{array}{llll}28 & 41 & 29 & 3.9\end{array}$

$\begin{array}{llll}39 & -24 & -23 & 3.8\end{array}$

$\begin{array}{llll}42 & 50 & 0 & 3.7\end{array}$

$\begin{array}{llll}-10 & 44 & 20 & 3.6\end{array}$

$\begin{array}{llll}-28 & 46 & 27 & 3.5\end{array}$

$\begin{array}{llll}-48 & -40 & -20 & 3.4\end{array}$

$\begin{array}{llll}-24 & 8 & 56 & 3.3\end{array}$

$\begin{array}{llll}-46 & -10 & -27 & 3.3\end{array}$

$\begin{array}{llll}-48 & -17 & -25 & 3.2\end{array}$

$\begin{array}{llll}-10 & 35 & -13 & 3.2\end{array}$

$\begin{array}{llll}53 & 1 & -2 & 3.2\end{array}$

$\begin{array}{llll}35 & -1 & -34 & 3.1\end{array}$

$\begin{array}{llll}28 & -13 & 58 & 3.1\end{array}$

$\begin{array}{llll}62 & -19 & -7 & 3.1\end{array}$ $x \quad y \quad z \quad z$-score

$\begin{array}{llll}-24 & 35 & 43 & 3.6\end{array}$

Locations in Talairach (Talairach and Tournoux, 1988) coordinates $(\mathrm{mm}):+x$, right; $-x$, left; $+y$, anterior; $+z$, superior. $A C C$, anterior cingulate cortex.

against $A D$ despite carrying the risk alleles (i.e., sampling bias).

(3) E4 homozygotes showed the greatest degree of amyloid deposition in bilateral putamen. Numerous studies as noted below have shown that the PCC/ precuneus and prefrontal cortices have high amyloid loads in cognitively normal adults, early-onset $A D$, LOAD, and those carrying AD-relevant mutations. However, mutation carriers show highest amyloid deposition in striatum.

(4) The E4 homozygotes showed no hypometabolism in the putamen, the principal site of amyloid deposition. This is consistent with studies of preclinical and clinical carriers of AD-relevant mutations.

(5) Extensive accumulation of amyloid in E4 homozygotes localized to several additional regions including the ACC, medial frontal, middle frontal, inferior temporal, middle temporal, superior temporal, and occipital regions.

\section{Hypometabolism in AD, E4, and autosomal dominant carriers \\ Metabolic changes in $A D$}

FDG PET remains among the best methods to evaluate functional brain decline in cognitively intact E4 carriers as well as in both preclinical and clinical early-onset $A D$ (EOAD) and sporadic LOAD. EOAD is classified typically as onset before age $65 \mathrm{y}$. Many studies of EOAD do not systematically screen to exclude carriers of known mutations. Across studies, the greatest consistency and degree of hypometabolism localizes to the PCC/precuneus (see below). It was unanticipated that the MTL was not the principal region of hypometabolism given its role in memory, site of tau deposition, and atrophy in normal aging and $A D$. However, the large partial volume effects and interslice distances in early PET scanners likely reduced sensitivity to detection.

Kim et al. (2005) studied 74 EOAD ( $<65$ y; CDR 0.5) using FDG PET. They reported more severe hypometabolism in parietal, frontal, and subcortical (basal ganglia and thalamus) areas compared with LOAD, interpreted as a more rapid deteriorating course. Rabinovici et al. (2010) reported EOAD ( $<65 \mathrm{y}$ ) had more severe deficits in working memory and attention. EOAD had more severe PCC and bilateral temporoparietal hypometabolism than LOAD; LOAD did not show relative decreases in metabolism compared to EOAD. EOAD had lower metabolism after atrophy correction than LOAD in bilateral precuneus and right angular gyrus; no regions in LOAD were less metabolic than in EOAD. There was a positive correlation between age of onset and hypometabolism in the precuneus, lateral parietal, and occipital regions.

The initial region of hypometabolism in early LOAD localized typically to the PCC/precuneus with subsequent extension into biparietal and inferior temporal regions (Minoshima et al., 1994, 1997). Despite the noteworthy absence of MTL hypometabolism in early studies, most subsequent studies using FDG PET on higher resolution scanners or with interleaf acquisition demonstrated hypometabolism in the MTL along the continuum from normal to $\mathrm{MCl}$ to $\mathrm{AD}$; this hypometabolism predicted subsequent cognitive decline (Mosconi et al., 2008; Chen et al., 2010; Lehmann et al., 2014).

\section{Metabolic changes with carriage of E4 allele}

Several studies examined alterations in metabolism in presymptomatic subjects and LOAD relative to E4 allele status. Small et al. (1995) compared FDG PET scans from cognitively intact subjects (age $\sim 55 \mathrm{y}$ ) with mild memory complaints both with $(n=12)$ and without $(n=19)$ the E4 allele. They found that E4 carriers had marked hypometabolism in both parietal lobes. Reiman et al. (2001) compared metabolic decline over a 2-y interval in cognitively normal APOE carriers versus noncarriers $(50-63 \mathrm{y})$. They demonstrated, despite the absence of cognitive change during follow-up, significantly less metabolism in carriers localized to lateral temporal cortex, PCC, lateral prefrontal cortex, basal forebrain, parahippocampal/lingual gyri, and thalamus. Langbaum et al. (2009) compared FDG PET scans from elder normal control subjects and patients with amnestic $\mathrm{MCl}$ and $\mathrm{AD}$. Despite higher resolution (8 $\mathrm{mm}$ FWHM) scans, medial temporal hypometabolism was detected bilaterally only in the AD patients compared with control subjects. There was hypometabolism in bilateral precuneus and left lateral parietal lobe in normal subjects with E4 allele compared with those without E4 $(n=21$ and 61 in each group, respectively).

In a landmark publication, Reiman et al. (1996) contrasted (1) FDG PET of 11 cognitively intact E4 homozygotes with 22 healthy controls without the E4 allele (mean group age: 55 and $56 \mathrm{y}$, respectively); and (2) FDG PET of 37 probable $A D$ patients with 22 healthy controls (each group of average $64 \mathrm{y}$ old). The probable AD patients 
relative to matched controls showed three broad regions of hypometabolism: PCC/precuneus as well as bilateral parietal and bilateral inferior temporal lobes. In addition, there were several small foci of hypometabolism in the prefrontal, occipital, and lateral temporal regions. Medial temporal hypometabolism was not reported in the $A D$ patients. In the contrast involving E4 homozygotes versus those without E4 allele, several hypometabolic foci converged with the $A D$ hypometabolic regions, including the PCC/precuneus, parietal, and inferior temporal cortices. Of note, the E4 homozygotes also had broad regions of significant hypometabolism in the prefrontal cortices, as well as smaller foci distributed throughout the cortex and cerebellum, not seen in the AD group.

In a subsequent study, Reiman et al. (2004) used FDG PET to examine healthy middle-aged adults (20-39 y). Twelve E4 heterozygotes compared with 15 E4 noncarriers showed some overlap with hypometabolic regions seen in $A D$, particularly in $P C C /$ precuneus as well as in parietal and inferior temporal regions. Medial temporal changes were not reported. The heterozygotes showed several regions of hypometabolism in prefrontal cortex beyond those seen in $A D$ patients. So, hypometabolism can arise both within and outside AD-affected regions, even in much younger healthy subjects.

De Leon et al. (2001) noted in a longitudinal study that those having cognitive decline from normal status at baseline showed lateral temporal lobe hypometabolism dependent on E4 status; the entorhinal cortex did not show this effect. Mosconi et al. (2004) compared using FDG PET AD patients with and without the E4 allele. They noted an age-by-genotype interaction in the anterior cingulate and medial frontal cortices. The results were interpreted as indicating an age-dependent aggravation in metabolic decline in $A D$ related to the $\mathrm{E} 4$ allele status.

To investigate the effects of ethnicity on the relationship of APOE status to glucose metabolism, cognitively intact, middle-aged (mean $\sim 55$ y) Latino Mexican-Americans were studied with FDG PET (Langbaum et al., 2010). The left hippocampus had decreased metabolism in E4 carriers versus noncarriers ( $n=11$ and 16 per group, respectively). There was some convergence of medial and lateral parietal hypometabolism in the contrast between E4 carriers versus noncarriers with the hypometabolism seen in LOAD. However, the E4 carriers showed less hypometabolism in the traditional precuneus/PCC regions with more extensive involvement of the ACC.

In contrast, Protas et al. (2013) examined with defined regions of interest a large series of healthy subjects (mean age $\sim 56$ y) who carried either 0,1 , or 2 E4 alleles ( $n=76$, 42 , and 31 , respectively). Those authors noted a highly significant difference across groups in PCC metabolism; no difference in hippocampal metabolism or volume was found. Differences in subject groups, technologies, or analysis methods could account for the divergence in results from those reported here. First, the much smaller sample of homozygotes in the present study compared to that of Protas et al. (2013) could explain the failure to detect PCC hypometabolism; even the changes in the MTL reported here were not large, although there was some subthreshold hypometabolism in the contralateral hippocampus. The left hippocampal hypometabolism in normal E4 carriers reported here does converge with the observation of Langbaum et al. (2010). Second, the earlier-generation scanner used by Protas et al. (2013) had an interslice distance of $3.375 \mathrm{~mm}$; this slice thickness without 3D acquisition or volume reconstruction would decrease recovery of the thin strip of MTL extending inferiorly from posterior to anterior as seen in Fig. 1 in the present report. Third, the mean age of the homozygotes here was much greater than that in Protas et al. (2013). Fourth, the present analysis used a voxel-wise approach, whereas Protas et al. (2013) used defined regions of interest. Finally, Protas et al. (2013) did not report amyloid deposition or longitudinal outcomes that could impact metabolism across subjects and studies.

\section{Metabolic changes in autosomal dominant mutation car- riers}

Several studies have examined with FDG PET the metabolic changes in mutation carriers including APP dosage effects (trisomy 21/Down syndrome; APP duplication; exon deletion variant) as well as mutations in PSEN1, PSEN2, and APP. Villemagne et al. (2009) found that the classic PCC and biparietal pattern of hypometabolism seen in sporadic $A D$ was not as evident in mutation carriers $(n=8$; CDR $0-3.0)$. No distinct pattern of FDG hypometabolism characterized the various PSEN1 versus APP mutation carriers; three individuals showed an almost normal pattern of uptake including the striatum, the principal locus of amyloid deposition. There was no relation between the hypometabolic pattern in the cortex or striatum and disease severity, type of mutation, or cognitive status. Schöll et al. (2012) reported on two APParc mutation carriers showing AD-typical patterns of hypometabolism. Sabbagh et al. (2015) reported in Down syndrome without dementia (mean age $\sim 36$ y) mostly hypometabolism and decreased gray matter atrophy in the ACC not PCC. Therefore, considerable variability in metabolism is seen in mutation carriers.

\section{Amyloid deposits in EOAD, LOAD, E4 carriers, and autosomal mutation carriers \\ Amyloid deposits in $A D$}

Neuropathologically, nondemented control subjects do not show amyloid deposition or neurofibrillary changes (Braak and Braak, 1991). In contrast, patients with AD show not only extensive fibrillar amyloid, but also an abundance of amyloid deposits that are diffuse without neurofibrillary changes or glial reaction (Braak and Braak, 1991; Brilliant et al., 1997). The striatum develops senile neuritic plaques and neurofibrillary tangles later in the progression of AD (Braak stage V-VI; Braak and Braak, 1991).

Amyloid imaging labels fibrillar amyloid (Ikomonovic et al., 2008; Clark et al., 2011; Curtis et al., 2015). Other forms of amyloid (diffuse, fleecy, deposits in AD cerebellum, amyloid oligomers) are not detected. In $A D$, the greatest fibrillar amyloid deposition localizes to the parietal cortex (both precuneus/PCC and lateral parietal); parietal fibrillar amyloid deposition often shows a correlation 
with declining parietal metabolism and synaptic markers (Klunk et al., 2004; Li et al., 2008; Scheff et al., 2015). Subsequently, fibrillar amyloid deposits spread throughout the neocortex including ACC, lateral prefrontal cortex, striatum, and the temporal lobe. Differences in amyloid deposition between EOAD and LOAD have depended on the region of interest. Rabinovici et al. (2010) studied 18 EOAD and compared them to 16 LOAD. They found no effect on amyloid deposition but decreasing metabolism in posterior brain regions depending on age of onset. Youn et al. (2017) studied nine EOAD, 11 LOAD, and 8 normal controls. EOAD patients were screened negative for the common $A D$-associated mutations. EOAD patients showed greater amyloid deposition only in the thalamus and basal ganglia compared to those with LOAD.

\section{Amyloid deposits and APOE*E4}

The major locus of amyloid deposition found here in E4 homozygotes localized to the putamen as well as several other regions $(A C C$, medial frontal, middle frontal, inferior temporal, middle temporal, superior temporal, and occipital). Unlike what is seen in typical LOAD, neither hypometabolism nor amyloid deposition localized to the PCC in these E4 homozygotes. It is noteworthy that the localization of fibrillar amyloid in healthy elders and in $A D$ does not reflect the patterns of cortical thinning, hypometabolism, or clinical phenotypes; these appear to converge with the localization of tau (Ossenkoppele et al., 2016; Schöll et al., 2016; Xia et al., 2017; Lockhart et al., 2017; Pontecorvo et al., 2017).

The pattern of amyloid deposition noted here is not inconsistent with that reported by Reiman et al. (2009). They studied a younger group (mean age $\sim 63 \mathrm{y}$ ) of 8 homozygotes, 12 heterozygotes, and 12 noncarriers of E4. They reported a significant association with "ADaffected mean cortical, frontal, temporal, posterior cingulate-precuneus, parietal, and basal ganglia ROls." Based on an estimation of their basal ganglia data, reanalysis specifically comparing E4 homozygotes to noncarriers, analogous to that done here, produced $p<0.01$ (twotailed, between-sample $t$ test; $\mathrm{df}=18$; heteroscedastic correction) indicating convergence in findings. Given the older age of the current homozygotes, amyloid deposition here appeared grossly greater overall than that reported by Reiman et al. (2009).

\section{Amyloid deposits in autosomal dominant mutations}

Genetic familial effects beyond those associated with the E4 allele have been reported with APP gene dose (trisomy 21/Down syndrome; APP duplication) as well as mutations in PSEN1, PSEN2, and APP. Putaminal amyloid deposits, which can correlate with age early in the course, were seen in Down syndrome without dementia (Handen et al., 2012; Lao et al., 2016). Braak stage (based on tau scans), amyloid deposition, and cognitive decline were correlated with age in amyloid-positive, nondemented subjects with Down syndrome; glucose hypometabolism and tau did not localize to the striatum, although regions with hypometabolism overlapped areas with tau deposition (Rafii et al., 2017). High levels of amyloid in the putamen were reported also in various cases of preclinical and clinical AD related to PSEN1, PSEN2, and APP mutations (Klunk et al., 2007; Remes et al., 2008; Koivunen et al., 2008; Villemagne et al., 2009; Fleisher et al., 2012; Shi et al., 2015; Rodriguez-Vieitez et al., 2016). Like observations here about E4 homozygotes, AD mutation carriers with putaminal amyloid deposits did not show hypometabolism in the putamen (Rodriguez-Vieitez et al., 2016).

The clinical significance of striatal amyloid deposition is unclear. The co-occurrence of Parkinson's in $A D$ is well known. $A D$ variants with mutations such as APP can also have various motor manifestations such as hyperactive reflexes, extremity weakness, and spastic paraparesis. An increased incidence of Parkinson's in subjects with Down syndrome with or without dementia remains controversial (Hestnes et al., 1997).

\section{Limitations}

The major limitation of this study is the small number of homozygotes available in the ADNI database, not surprising given their low frequency. The ALZGENE database indicates an E4/E4 prevalence of $\sim 2 \%$ in controls and $15 \%$ in AD cases (Alzforum, 2017). Furthermore, the frequency of E4/E4 decreases with aging, most likely owing to differential survival related to cardiovascular disease. In an Australian community sample of those $70 \mathrm{y}$ or older surviving a follow-up period of $3 \mathrm{y}$, the E4 allele frequency was $13 \%$ (Henderson et al., 1995). Of these 638 subjects, only $10 \mathrm{E} 4$ homozygotes were recruited, and none were older than $90 \mathrm{y}$. Larger samples will require pooling across multiple databases. The limited sample described here risks type II errors; thus, the present findings must be considered preliminary, particularly regarding the absence of changes in various regions. Nevertheless, the present findings are noteworthy given the differences from LOAD and similarities to AD-related mutations and Down syndrome.

Another issue concerns whether the homozygotes represent typical preclinical $A D$ or whether the sample is biased (e.g., survival bias). Despite normal cognitive status, approximately half were already positive for amyloid by the usual criteria (ADNI's templated SUVR). Their mean age of $\sim 76 \mathrm{y}$ is near the peak age $(60-75 \mathrm{y})$ for the highest risk of conversion from normal cognition to $\mathrm{MCl}$ or $\mathrm{AD}$ (Bonham et al., 2016). The predicted age for onset of LOAD in E4 homozygotes has been estimated at 5-7 y earlier than for noncarriers (Blacker et al., 1997; Sando et al., 2008).

No atrophy correction was made for the measurements of glucose metabolism in this study. The between-group comparison minimized age-related atrophy across groups by matching on age. The rationale for not performing atrophy correction considered that depending on the algorithm, amplification of noise compounded by the small sample size can introduce additional concerns. The question of PCC and medial temporal atrophy in cognitively normal E4 carriers is controversial given mixed results from different studies. For example, Li et al. (2016) found greater atrophy of the left hippocampus in E4 carrier versus noncarrier groups without dementia (i.e., control 
and $\mathrm{MCl}$ combined) from $\mathrm{ADNI}(n=212$ and 242 per group, respectively). Haller et al. (2017) studied adults $(n=282)$ dwelling in the community who were cognitively intact and followed for $18 \mathrm{mo}$. They found a significant effect of the E4 allele on PCC atrophy but only for those who decline on follow-up; no changes were found in the MTL. The MTL in elderly with intact cognition is known to have tau tangles typically associated with neurodegeneration, whether amyloid positive or negative, and may explain the observed hypometabolism found in this study (Bouras et al., 1994; Braak and Del Tredici, 2015).

\section{Summary}

In conclusion, cognitively normal, elderly E4/E4 show an atypical pattern of both hypometabolism and amyloid deposition compared with that known to occur in LOAD. Metabolism is dissociated in localization from amyloid deposition. The region of greatest amyloid deposition localizes to the putamen, as is seen in Down syndrome and early-onset $A D$ arising from mutations. The mechanisms for protein deposition remain unclear. The difference in biomarker phenotypes between E4 homozygotes and those with LOAD suggest divergent pathophysiological processes, unshared environmental effects, or residuals of resilience to $A D$ in a high-risk group.

\section{References}

Alzforum (2017) Alzgene: meta-analysis of all published AD association studies (case-control only) APOE e2/3/4. In: Biomedical Research Forum. Available at http://www.alzgene.org/ meta.asp?genelD $=83$.

Blacker D, Haines JL, Rodes L, Terwedow H, Go RC, Harrell LE, Perry RT, Bassett SS, Chase G, Meyers D, Albert MS, Tanzi R (1997) APOE-4 and age at onset of Alzheimer's disease: the NIMH genetics initiative. Neurology 48:139-147. Medline

Bonham LW, Geier EG, Fan CC, Leong JK, Besser L, Kukull WA, Kornak J, Andreassen OA, Schellenberg GD, Rosen HJ, Dillon WP, Hess CP, Miller BL, Dale AM, Desikan RS, Yokoyama JS (2016) Age-dependent effects of APOE epsilon4 in preclinical Alzheimer's disease. Ann Clin Transl Neurol 3:668-677. CrossRef Medline

Bouras C, Hof PR, Giannakopoulos P, Michel JP, Morrison JH (1994) Regional distribution of neurofibrillary tangles and senile plaques in the cerebral cortex of elderly patients: a quantitative evaluation of a one-year autopsy population from a geriatric hospital. Cereb Cortex 4:138-150. Medline

Braak H, Braak E (1991) Neuropathological staging of Alzheimerrelated changes. Acta Neuropathol 82:239-259. Medline

Braak H, Del Tredici K (2015) The preclinical phase of the pathological process underlying sporadic Alzheimer's disease. Brain 138: 2814-2833. CrossRef Medline

Brilliant MJ, Elble RJ, Ghobrial M, Struble RG (1997) The distribution of amyloid beta protein deposition in the corpus striatum of patients with Alzheimer's disease. Neuropathol Appl Neurobiol 23: 322-325. Medline

Chen K, Langbaum JB, Fleisher AS, Ayutyanont N, Reschke C, Lee W, Liu X, Bandy D, Alexander GE, Thompson PM, Foster NL, Harvey DJ, de Leon MJ, Koeppe RA, Jagust WJ, Weiner MW, Reiman EM Alzheimer's Disease Neuroimaging Initiative. (2010) Twelve-month metabolic declines in probable Alzheimer's disease and amnestic mild cognitive impairment assessed using an empirically pre-defined statistical region-of-interest: findings from the Alzheimer's Disease Neuroimaging Initiative. Neuroimage 51:654664. CrossRef

Clark CM, et al. (2011) Use of florbetapir-PET for imaging betaamyloid pathology. JAMA 305:275-283. CrossRef Medline
Curtis C, et al. (2015) Phase 3 trial of flutemetamol labeled with radioactive fluorine 18 imaging and neuritic plaque density. JAMA Neurol 72:287-294. CrossRef Medline

de Leon MJ, Convit A, Wolf OT, Tarshish CY, DeSanti S, Rusinek H, Tsui W, Kandil E, Scherer AJ, Roche A, Imossi A, Thorn E, Bobinski M, Caraos C, Lesbre P, Schlyer D, Poirier J, Reisberg B, Fowler J (2001) Prediction of cognitive decline in normal elderly subjects with 2-[(18)F]fluoro-2-deoxy-d-glucose/positron-emission tomography (FDG/PET). Proc Natl Acad Sci U S A 98:10966-10971. CrossRef

Donohue MC, Sperling RA, Petersen R, Sun CK, Weiner MW, Aisen PS Alzheimer's Disease Neuroimaging Initiative. (2017) Association between elevated brain amyloid and subsequent cognitive decline among cognitively normal persons. JAMA 317:2305-2316. CrossRef Medline

Doraiswamy PM, Sperling RA, Johnson K, Reiman EM, Wong TZ, Sabbagh MN, Sadowsky CH, Fleisher AS, Carpenter A, Joshi AD, Lu M, Grundman M, Mintun MA, Skovronsky DM, Pontecorvo MJ, Group AAS, Group AAS (2014) Florbetapir F-18 amyloid PET and 36-month cognitive decline: a prospective multicenter study. Mol Psychiatry 19:1044-1051. CrossRef

Farrer LA, Cupples LA, Haines JL, Hyman B, Kukull WA, Mayeux R, Myers RH, Pericak-Vance MA, Risch N, van Duijn CM (1997) Effects of age, sex, and ethnicity on the association between apolipoprotein E genotype and Alzheimer disease. A metaanalysis. APOE and Alzheimer Disease Meta-analysis Consortium. JAMA 278:1349-1356. Medline

Fleisher AS, et al. (2012) Florbetapir PET analysis of amyloid-beta deposition in the presenilin 1 E280A autosomal dominant Alzheimer's disease kindred: a cross-sectional study. Lancet Neurol 11:1057-1065. CrossRef Medline

Genin E, et al. (2011) APOE and Alzheimer disease: a major gene with semi-dominant inheritance. Mol Psychiatry 16:903-907. CrossRef Medline

Haller S, Montandon ML, Rodriguez C, Ackermann M, Herrmann FR, Giannakopoulos P (2017) APOE*E4 is associated with gray matter loss in the posterior cingulate cortex in healthy elderly controls subsequently developing subtle cognitive decline. AJNR Am J Neuroradiol 38:1335-1342. CrossRef Medline

Handen BL, Cohen AD, Channamalappa U, Bulova P, Cannon SA, Cohen WI, Mathis CA, Price JC, Klunk WE (2012) Imaging brain amyloid in nondemented young adults with Down syndrome using Pittsburgh Compound B. Alzheimers Dement 8:496-501. CrossRef Medline

Henderson AS, Easteal S, Jorm AF, Mackinnon AJ, Korten AE, Christensen H, Croft L, Jacomb PA (1995) Apolipoprotein E allele epsilon 4, dementia, and cognitive decline in a population sample. Lancet 346:1387-1390. Medline

Hestnes A, Daniel SE, Lees AJ, Brun A (1997) Down's syndrome and Parkinson's disease. J Neurol Neurosurg Psychiatry 62:289Medline

Ikonomovic MD, Klunk WE, Abrahamson EE, Mathis CA, Price JC, Tsopelas ND, Lopresti BJ, Ziolko S, Bi W, Paljug WR, Debnath ML, Hope CE, Isanski BA, Hamilton RL, DeKosky ST (2008) Postmortem correlates of in vivo PIB-PET amyloid imaging in a typical case of Alzheimer's disease. Brain 131:1630-1645. CrossRef

Kim EJ, Cho SS, Jeong Y, Park KC, Kang SJ, Kang E, Kim SE, Lee $\mathrm{KH}, \mathrm{Na} \mathrm{DL}$ (2005) Glucose metabolism in early onset versus late onset Alzheimer's disease: an SPM analysis of 120 patients. Brain 128:1790-1801. CrossRef Medline

Klunk WE, et al. (2004) Imaging brain amyloid in Alzheimer's disease with Pittsburgh Compound-B. Ann Neurol 55:306-319. CrossRef Medline

Klunk WE, et al. (2007) Amyloid deposition begins in the striatum of presenilin-1 mutation carriers from two unrelated pedigrees. $J$ Neurosci 27:6174-6184. CrossRef Medline

Koivunen J, Verkkoniemi A, Aalto S, Paetau A, Ahonen JP, Viitanen M, Någren K, Rokka J, Haaparanta M, Kalimo H, Rinne JO (2008) PET amyloid ligand [(11)C]PIB uptake shows predominantly striatal 
increase in variant Alzheimer's disease. Brain 131:1845-1853. CrossRef Medline

Lancaster JL, Woldorff MG, Parsons LM, Liotti M, Freitas CS, Rainey L, Kochunov PV, Nickerson D, Mikiten SA, Fox PT (2000) Automated Talairach atlas labels for functional brain mapping. Hum Brain Mapp 10:120-131. Medline

Langbaum JB, Chen K, Lee W, Reschke C, Bandy D, Fleisher AS, Alexander GE, Foster NL, Weiner MW, Koeppe RA, Jagust WJ, Reiman EM (2009) Categorical and correlational analyses of baseline fluorodeoxyglucose positron emission tomography images from the Alzheimer's Disease Neuroimaging Initiative (ADNI). Neuroimage 45:1107-1116. CrossRef

Langbaum JB, Chen K, Caselli RJ, Lee W, Reschke C, Bandy D, Alexander GE, Burns CM, Kaszniak AW, Reeder SA, Corneveaux JJ, Allen AN, Pruzin J, Huentelman MJ, Fleisher AS, Reiman EM (2010) Hypometabolism in Alzheimer-affected brain regions in cognitively healthy Latino individuals carrying the apolipoprotein $\mathrm{E}$ epsilon4 allele. Arch Neurol 67:462-468. CrossRef Medline

Lao PJ, Betthauser TJ, Hillmer AT, Price JC, Klunk WE, Mihaila I, Higgins AT, Bulova PD, Hartley SL, Hardison R, Tumuluru RV, Murali D, Mathis CA, Cohen AD, Barnhart TE, Devenny DA, Mailick MR, Johnson SC, Handen BL, Christian BT (2016) The effects of normal aging on amyloid-beta deposition in nondemented adults with Down syndrome as imaged by carbon 11-labeled Pittsburgh Compound B. Alzheimers Dement 12:380-390. CrossRef Medline

Lehmann M, Ghosh PM, Madison C, Karydas A, Coppola G, O'Neil JP, Huang Y, Miller BL, Jagust WJ, Rabinovici GD (2014) Greater medial temporal hypometabolism and lower cortical amyloid burden in APOE4-positive AD patients. J Neurol Neurosurg Psychiatry 85:266-273. CrossRef Medline

Li B, Shi J, Gutman BA, Baxter LC, Thompson PM, Caselli RJ, Wang Y Alzheimer's Disease Neuroimaging Initiative. (2016) Influence of APOE genotype on hippocampal atrophy over time: an $n=1925$ surface-based ADNI study. PLoS One 11:e0152901. CrossRef

Li Y, Rinne JO, Mosconi L, Pirraglia E, Rusinek H, DeSanti S, Kemppainen N, Någren K, Kim BC, Tsui W, de Leon MJ (2008) Regional analysis of FDG and PIB-PET images in normal aging, mild cognitive impairment, and Alzheimer's disease. Eur J Nucl Med Mol Imaging 35:2169-2181. CrossRef Medline

Lockhart SN, Schöll M, Baker SL, Ayakta N, Swinnerton KN, Bell RK, Mellinger TJ, Shah VD, O'Neil JP, Janabi M, Jagust WJ (2017) Amyloid and tau PET demonstrate region-specific associations in normal older people. Neuroimage 150:191-199. CrossRef Medline

Minoshima S, Foster NL, Kuhl DE (1994) Posterior cingulate cortex in Alzheimer's disease. Lancet 344:895. Medline

Minoshima S, Giordani B, Berent S, Frey KA, Foster NL, Kuhl DE (1997) Metabolic reduction in the posterior cingulate cortex in very early Alzheimer's disease. Ann Neurol 42:85-94. CrossRef Medline

Monsell SE, Kukull WA, Roher AE, Maarouf CL, Serrano G, Beach TG, Caselli RJ, Montine TJ, Reiman EM (2015) Characterizing apolipoprotein E epsilon4 carriers and noncarriers with the clinical diagnosis of mild to moderate Alzheimer dementia and minimal beta-amyloid peptide plaques. JAMA Neurology 72:1124-1131. CrossRef Medline

Morris JC, Roe CM, Xiong C, Fagan AM, Goate AM, Holtzman DM, Mintun MA (2010) APOE predicts amyloid-beta but not tau Alzheimer pathology in cognitively normal aging. Ann Neurol 67:122131. CrossRef

Mosconi L, De Santi S, Li J, Tsui WH, Li Y, Boppana M, Laska E, Rusinek H, de Leon MJ (2008) Hippocampal hypometabolism predicts cognitive decline from normal aging. Neurobiol Aging 29:676-692. CrossRef Medline

Mosconi L, Sorbi S, Nacmias B, De Cristofaro MT, Fayyaz M, Bracco L, Herholz K, Pupi A (2004) Age and APOE genotype interaction in Alzheimer's disease: An FDG-PET study. Psychiatry Res 130:141151. CrossRef Medline

Murray J, Tsui WH, Li Y, McHugh P, Williams S, Cummings M, Pirraglia E, Solnes L, Osorio R, Glodzik L, Vallabhajosula S, Drzezga A, Minoshima S, de Leon MJ, Mosconi L (2014) FDG and amyloid PET in cognitively normal individuals at risk for late-onset
Alzheimer's disease. Adv J Mol Imaging 4:15-26. CrossRef Medline

Ossenkoppele R, Schonhaut DR, Schöll M, Lockhart SN, Ayakta N, Baker SL, O'Neil JP, Janabi M, Lazaris A, Cantwell A, Vogel J, Santos M, Miller ZA, Bettcher BM, Vossel KA, Kramer JH, GornoTempini ML, Miller BL, Jagust WJ, Rabinovici GD (2016) Tau PET patterns mirror clinical and neuroanatomical variability in Alzheimer's disease. Brain 139:1551-1567. CrossRef Medline

Pontecorvo MJ, Devous MD, Sr., Navitsky M, Lu M, Salloway S, Schaerf FW, Jennings D, Arora AK, McGeehan A, Lim NC, Xiong $H$, Joshi AD, Siderowf A, Mintun MA, 18F-AV-1451-A05 Investigators. (2017) Relationships between flortaucipir PET tau binding and amyloid burden, clinical diagnosis, age and cognition. Brain 140: 748-763.

Protas HD, Chen K, Langbaum JB, Fleisher AS, Alexander GE, Lee W, Bandy D, de Leon MJ, Mosconi L, Buckley S, Truran-Sacrey D, Schuff N, Weiner MW, Caselli RJ, Reiman EM (2013) Posterior cingulate glucose metabolism, hippocampal glucose metabolism, and hippocampal volume in cognitively normal, late-middle-aged persons at 3 levels of genetic risk for Alzheimer disease. JAMA Neurology 70:320-325. CrossRef Medline

Rabinovici GD, Furst AJ, Alkalay A, Racine CA, O'Neil JP, Janabi M, Baker SL, Agarwal N, Bonasera SJ, Mormino EC, Weiner MW, Gorno-Tempini ML, Rosen HJ, Miller BL, Jagust WJ (2010) Increased metabolic vulnerability in early-onset Alzheimer's disease is not related to amyloid burden. Brain 133:512-528. CrossRef

Rafii MS, Lukic AS, Andrews RD, Brewer J, Rissman RA, Strother SC, Wernick MN, Pennington C, Mobley WC, Ness S, Matthews DC, Down Syndrome Biomarker Initiative, the Alzheimer's Disease Neuroimaging Initiative. (2017) PET imaging of tau pathology and relationship to amyloid, longitudinal MRI, and cognitive change in Down syndrome: results from the Down Syndrome Biomarker Initiative (DSBI). J Alzheimers Dis 60:439-450. CrossRef Medline

Reiman EM, Caselli RJ, Yun LS, Chen K, Bandy D, Minoshima S, Thibodeau SN, Osborne D (1996) Preclinical evidence of Alzheimer's disease in persons homozygous for the epsilon 4 allele for apolipoprotein E. N Engl J Med 334:752-758. CrossRef Medline

Reiman EM, Caselli RJ, Chen K, Alexander GE, Bandy D, Frost J (2001) Declining brain activity in cognitively normal apolipoprotein E epsilon 4 heterozygotes: A foundation for using positron emission tomography to efficiently test treatments to prevent Alzheimer's disease. Proc Natl Acad Sci U S A 98:3334-3339. CrossRef Medline

Reiman EM, Chen K, Alexander GE, Caselli RJ, Bandy D, Osborne D, Saunders AM, Hardy J (2004) Functional brain abnormalities in young adults at genetic risk for late-onset Alzheimer's dementia. Proc Natl Acad Sci U S A 101:284-289. CrossRef Medline

Reiman EM, Chen K, Liu X, Bandy D, Yu M, Lee W, Ayutyanont N, Keppler J, Reeder SA, Langbaum JB, Alexander GE, Klunk WE, Mathis CA, Price JC, Aizenstein HJ, DeKosky ST, Caselli RJ (2009) Fibrillar amyloid-beta burden in cognitively normal people at 3 levels of genetic risk for Alzheimer's disease. Proc Natl Acad Sci U S A 106:6820-6825. CrossRef Medline

Remes AM, Laru L, Tuominen H, Aalto S, Kemppainen N, Mononen H, Någren K, Parkkola R, Rinne JO (2008) Carbon 11-labeled Pittsburgh Compound B positron emission tomographic amyloid imaging in patients with APP locus duplication. Arch Neurol 65: 540-544. CrossRef Medline

Rodriguez-Vieitez E, Saint-Aubert L, Carter SF, Almkvist O, Farid K, Schöll M, Chiotis K, Thordardottir S, Graff C, Wall A, Långstrom B, Nordberg A (2016) Diverging longitudinal changes in astrocytosis and amyloid PET in autosomal dominant Alzheimer's disease. Brain 139:922-936. CrossRef Medline

Sabbagh MN, Chen K, Rogers J, Fleisher AS, Liebsack C, Bandy D, Belden C, Protas H, Thiyyagura P, Liu X, Roontiva A, Luo J, Jacobson S, Malek-Ahmadi M, Powell J, Reiman EM (2015) Florbetapir PET, FDG PET, AND MRI in Down syndrome individuals with and without Alzheimer's dementia. Alzheimers Dement 11: 994-1004. CrossRef Medline 
Sando SB, Melquist S, Cannon A, Hutton ML, Sletvold O, Saltvedt I, White LR, Lydersen S, Aasly JO (2008) APOE epsilon 4 lowers age at onset and is a high risk factor for Alzheimer's disease: a case control study from central Norway. BMC Neurol 8:9. CrossRef Medline

Scheff SW, Price DA, Ansari MA, Roberts KN, Schmitt FA, Ikonomovic MD, Mufson EJ (2015) Synaptic change in the posterior cingulate gyrus in the progression of Alzheimer's disease. J Alzheimers Dis 43:1073-1090. CrossRef Medline

Schöll M, Lockhart SN, Schonhaut DR, O’Neil JP, Janabi M, Ossenkoppele R, Baker SL, Vogel JW, Faria J, Schwimmer HD, Rabinovici GD, Jagust WJ (2016) PET imaging of tau deposition in the aging human brain. Neuron 89:971-982. CrossRef Medline

Schöll M, Wall A, Thordardottir S, Ferreira D, Bogdanovic N, Långstrom B, Almkvist O, Graff C, Nordberg A (2012) Low PIB PET retention in presence of pathologic CSF biomarkers in Arctic APP mutation carriers. Neurology 79:229-236. CrossRef Medline

Shi Y, et al. (2017) Apoe4 markedly exacerbates tau-mediated neurodegeneration in a mouse model of tauopathy. Nature 549:523527. CrossRef

Shi Z, Wang Y, Liu S, Liu M, Liu S, Zhou Y, Wang J, Cai L, Huo YR, Gao S, Ji Y (2015) Clinical and neuroimaging characterization of Chinese dementia patients with PSEN1 and PSEN2 mutations. Dement Geriatr Cogn Disord 39:32-40. CrossRef Medline
Small GW, Mazziotta JC, Collins MT, Baxter LR, Phelps ME, Mandelkern MA, Kaplan A, La Rue A, Adamson CF, Chang L, et al. (1995) Apolipoprotein E type 4 allele and cerebral glucose metabolism in relatives at risk for familial Alzheimer disease. JAMA 273:942-947. Medline

Talairach J, Tournoux P. (1988) Coplanar Stereotaxic Atlas of the Human Brain. New York: Thieme.

Villemagne VL, Ataka S, Mizuno T, Brooks WS, Wada Y, Kondo M, Jones G, Watanabe Y, Mulligan R, Nakagawa M, Miki T, Shimada H, O'Keefe GJ, Masters CL, Mori H, Rowe CC (2009) High striatal amyloid beta-peptide deposition across different autosomal Alzheimer disease mutation types. Arch Neurol 66:1537-1544. CrossRef Medline

Xia C, Makaretz SJ, Caso C, McGinnis S, Gomperts SN, Sepulcre J, Gomez-Isla T, Hyman BT, Schultz A, Vasdev N, Johnson KA, Dickerson BC (2017) Association of in vivo [(18)F]AV-1451 tau PET imaging results with cortical atrophy and symptoms in typical and atypical Alzheimer disease. JAMA Neurology 74:427-436. CrossRef

Youn YC, Jang JW, Han SH, Kim H, Seok JW, Byun JS, Park KY, An SSA, Chun IK, Kim S (2017) 11C-PIB PET imaging reveals that amyloid deposition in cases with early-onset Alzheimer's disease in the absence of known mutations retains higher levels of PIB in the basal ganglia. Clin Interv Aging 12:1041-1048. CrossRef Medline 